Brit. F. industr. Med., 1967, 24, 320.

\title{
Metabolism of Ethylene Glycol Dinitrate and its Influence on the Blood Pressure of the Rat
}

\author{
D. G. CLARK and M. H. LITCHFIELD \\ From Imperial Chemical Industries Limited, Industrial Hygiene Research Laboratories, Alderley Park, \\ nr. Macclesfield, Cheshire
}

Breakdown of ethylene glycol dinitrate (EGDN) in blood in vitro results in the liberation of inorganic nitrite and ethylene glycol mononitrate (EGMN). The nitrite is oxidized to inorganic nitrate but the EGMN is more resistant to further degradation.

Similar metabolites are produced during the metabolism of EGDN in vivo. The nitrate is excreted in the urine and accounts for $60 \%$ of the injection. The EGMN released is almost completely metabolized, since only $1.5 \%$ of the injection can be detected as EGMN in the urine. Breakdown of EGMN in vivo is confirmed when the compound is injected; less than $0.5 \%$ is recovered as EGMN in the urine. Nitrite is released and oxidized to nitrate which is then excreted in the urine and accounts for $57 \%$ of the injection.

An injection of EGDN or EGMN causes a fall in blood pressure lasting several hours, EGDN being more effective. Since the fall in blood pressure and the concentrations of EGDN and its metabolites in the blood have been determined simultaneously, a correlation between blood pressure and blood concentrations has been attempted. It is suggested that the fall in blood pressure after an injection of EGDN could be the resultant of the actions of EGDN, EGMN, and nitrite. The initial fall in blood pressure may be due to the intact molecule of EGDN followed in turn by the effects of nitrite and EGMN released during the breakdown of the EGDN molecule.

Ethylene glycol dinitrate (EGDN) is used in the explosives industry as one of the components of anti-freeze dynamite. It is volatile and is readily absorbed via the lungs and skin (Gross, Bock, and Hellrung, 1942). Consequently, some of the workers engaged in the manufacture of dynamite may absorb EGDN throughout their working day. In common with other organic nitrates, such as nitroglycerine, EGDN lowers the blood pressure and often causes headaches in the workers (Carmichael and Lieben, 1963). Whereas the metabolism of nitroglycerine and certain other organic nitrates and their effects have been well documented, there is a lack of information on the behaviour of EGDN in the body.

This paper, therefore, is concerned with the metabolism of EGDN and some of the pharmacological properties of EGDN and its metabolites in the rat.

\section{Methods}

The animals used were specific pathogen-free female

Received for publication February 28, 1967 . rats of the Alderley Park (albino) strain, with body weights in the range 200 to $250 \mathrm{~g}$.

EGDN (supplied by I.C.I. Nobel Division as a $99 \cdot 1 \%$ pure material) was used as a $10 \%$ solution in corn oil for the in vivo studies and as a $1 \%$ solution in ethanol for in vitro work. Ethylene glycol mononitrate (EGMN) was synthesized by the method of Ferris, McLean, Marks, and Emmons (1953) and was used either as a $2 \%$ corn oil solution or as a $0.1 \%$ aqueous solution.

Rats were anaesthetized by an intraperitoneal injection of $60 \mathrm{mg}$. $/ \mathrm{kg}$. sodium pentobarbitone (Nembutal). The blood pressures of anaesthetized rats were recorded from a cannulated carotid artery by means of a Devices pressure transducer; mean blood pressures werc obtained by electronic damping of the transducer output. Display was by a Devices M4 high-speed pen-recorder. The blood pressure readings were noted 18 minutes after the injection of the anaesthetic when it was known that the cardiovascular system had stabilized.

Blood samples were taken from the carotid artery into tubes containing I mg. sodium fluoride and $2 \mathrm{mg}$. potassium oxalate per ml. of blood to prevent clotting and to inhibit the breakdown of inorganic nitrite and EGDN in the sample. Since complete inhibition of breakdown was not possible, the blood was analysed immediately after collection.

For the in vitro studies, blood was taken from a 
carotid artery into heparinized tubes. Plasma and erythrocytes were separated by centrifugation. Plasma was used undiluted; erythrocytes were washed and centrifuged three times with $0.2 \mathrm{~N}$ phosphate buffer at pH 7.4 and made up to the original blood volume with the phosphate buffer for use in the experiments.

Immediately after removal from an animal, or at the end of an in vitro experiment, $\mathrm{I} \mathrm{ml}$. of blood was diluted with I ml. of water and shaken with Io ml. of ether for I minute. Free EGDN present in the blood was transferred completely into the ether layer, whereas the inorganic nitrate and nitrite remained in the aqueous layer.

EGDN was determined in $5 \mathrm{ml}$. of the ether extract by a modification of the method of Hasegawa, Sato, Yoshikawa, Sakabe, Yamaguchi, and Hotta (1962). Absorbence was measured on a Unicam SP600 spectrophotometer at $540 \mathrm{~m} \mu$ and the EGDN present in $\mathrm{I} \mathrm{ml}$. of whole blood was calculated from calibration curves. Any EGMN present in the ether extract was not converted to nitrite under these conditions and consequently did not intefere with the estimation.

The aqueous layer remaining after the original ether extraction of the blood was extracted again with $10 \mathrm{ml}$. ether to remove any EGMN remaining. After separation, the blood was analysed for inorganic nitrate and inorganic nitrite on the Technicon AutoAnalyser as previously described (Litchfield, 1967).

Blood was analysed for EGMN by a modification of a gas chromatographic method developed for the estimation of EGDN (Williams, Murray, and Gibb, 1966). Two millilitres of blood were shaken with Io $\mathrm{ml}$. of ether for I minute, and the ether layer was removed, made to volume ( 5 to $50 \mathrm{ml}$.) and dried with anhydrous sodium sulphate. Two-microlitre portions of this ether extract were injected into a Wilkins 1522 gas chromatograph with an electron capture detector, interspaced with standard samples containing known quantities of EGMN. The column was a $30 \% \mathrm{E}_{3} \mathrm{OI}$ silicone gum phase on acid-washed BDH celite 80 to 120 mesh in a $5 \mathrm{ft}$. $\times \frac{1}{8}$ in. stainless steel tube. Column, injector, and detector temperatures were $130^{\circ} \mathrm{C}$., $165^{\circ} \mathrm{C}$., and $165^{\circ} \mathrm{C}$. respectively; nitrogen gas flow was 60 $\mathrm{ml}$./min. Every four hours the system was conditioned with 5- $\mu$ l. samples of an ethyl alcohol solution of nitroglycerine (I $\mu \mathrm{g} . / \mathrm{ml}$.). Under these conditions the retention times for EGMN and EGDN were $I \cdot 3$ minutes and $\mathrm{I} \cdot 9$ minutes respectively, giving adequate separation for the estimation. As the recovery of added EGMN from blood was $80 \%( \pm 2 \%)$, a correction was applied to all samples.

Organic nitrite in the blood was estimated by extracting $2 \mathrm{ml}$. of blood with $10 \mathrm{ml}$. of ether. Five millilitres of ether extract were then mixed with $7 \mathrm{ml}$. ethyl alcohol and I $\mathrm{ml}$. water and the nitrite was analysed by the colorimetric procedure of Shinn (194I).

Groups of rats were placed in metabolism cages and the urine, separated from the faeces (Gage, 196I), was collected in containers cooled by an acetone and solid carbon dioxide mixture. Water was given ad libitum but food was withheld during the experiment.
After suitable dilution, urine was analysed for EGDN, EGMN, inorganic nitrate, and inorganic nitrite by the techniques used for blood. All processing of the urine samples, up to and including the extraction procedures, was carried out in a cold room at $5^{\circ} \mathrm{C}$., as changes in the nitrate and nitrite contents were found to occur at higher temperatures.

\section{Results}

Blood was taken from human subjects, rabbits, and rats that had never been exposed to organic nitrates and was analysed for inorganic nitrate and inorganic nitrite. In all cases nitrite was found to be below the level of sensitivity of the method of estimation ( $<0 . \mathrm{I} \mu \mathrm{g} . / \mathrm{ml}$.) and the nitrate concentrations were approximately $\mathrm{I} \cdot 0 \mu \mathrm{g} . / \mathrm{ml}$.

Metabolism in vitro Rat blood was incubated at $37^{\circ} \mathrm{C}$. with $50 \mu \mathrm{g} . / \mathrm{ml}$. EGDN and samples were withdrawn at intervals for estimation of EGDN breakdown and the production of inorganic nitrate and nitrite. The results summarized in Table I show that breakdown was substantially complete within two hours. Inorganic nitrite was mostly

TABLE I

Metabolism of $50 \mu \mathrm{G}$. EGDN PER ML. OF WhOLE BLOOD AT $37^{\circ} \mathrm{C}$.

\begin{tabular}{c|c|c|c}
\hline Time (min.) & $\begin{array}{c}\text { EGDN } \\
\text { Breakdown } \\
(\%)\end{array}$ & $\begin{array}{c}\text { Inorganic } \\
\text { Nitrite } \\
(\mu g . / m l .)\end{array}$ & $\begin{array}{c}\text { Inorganic } \\
\text { Nitrate } \\
(\mu g . / m l .)\end{array}$ \\
\hline 15 & 22 & $1 \cdot 4$ & $2 \cdot 1$ \\
30 & 40 & $1 \cdot 7$ & $6 \cdot 9$ \\
60 & 82 & $1 \cdot 2$ & $12 \cdot 7$ \\
90 & 92 & 0.4 & 16.3 \\
120 & 99 & 0.3 & $20 \cdot 0$ \\
\hline
\end{tabular}

The results are the means of duplicate estimations.

produced during the initial stages of breakdown and was itself metabolized to nitrate. The end products of metabolism were inorganic nitrate and an organic nitrate which was found to be ethylene glycol mononitrate (EGMN).

Analysis of the blood 2.5 hours after incubation, when both EGDN and inorganic nitrite are absent, showed the presence of $20 \mu \mathrm{g}$. $/ \mathrm{ml}$. inorganic nitrate and $34^{\circ} \circ \mu \mathrm{g} . / \mathrm{ml}$. EGMN, which correlates well with the theoretical yields of $20 \mu \mathrm{g} . / \mathrm{ml}$. and $35.0 \mu \mathrm{g} . / \mathrm{ml}$. respectively. The in vitro breakdown of EGMN is very slow: incubation of $50 \mu \mathrm{g} . / \mathrm{ml}$. EGMN in whole blood at $37^{\circ} \mathrm{C}$. leads to the degradation of only $4 \%$ of the molecule after four hours. 
That breakdown of EGDN in the blood occurred in the erythrocytes was shown by incubating plasma and erythrocytes separately with $50 \mu \mathrm{g}$. $/ \mathrm{ml}$. EGDN. No breakdown occurred in the plasma after two hours but the breakdown in the erythrocytes was almost identical to that of whole blood.

Metabolism in vivo A group of 75 rats was used, each rat receiving $65 \mathrm{mg}$. $/ \mathrm{kg}$. EGDN subcutaneously. At each time interval after the injection separate groups of five rats were taken and blood pressure, blood EGDN, and blood inorganic nitrate and nitrite were estimated for each animal. Figure I summarizes the results. Free EGDN in
TABLE II

EGMN Production in vivo AFTER a Subcutaneous INJECTION OF 65 MG./KG. EGDN IN THE RAT

\begin{tabular}{c|c|c}
\hline Time (hours) & No. of Rats & $\begin{array}{c}\text { Blood EGMN } \\
(\mu \mathrm{g} . / \mathrm{ml} .)\end{array}$ \\
\hline 0.5 & 2 & $20 \cdot 5$ \\
1 & 3 & $27 \cdot 0(0.6)$ \\
2 & 5 & $29 \cdot 0(6.0)$ \\
3 & 4 & $32 \cdot 5(3.4)$ \\
5 & 5 & $23 \cdot 5(4.9)$ \\
8 & 5 & $10.8(4.7)$ \\
12 & 3 & $<0.25$ \\
\hline
\end{tabular}

Standard deviations are given in parentheses.
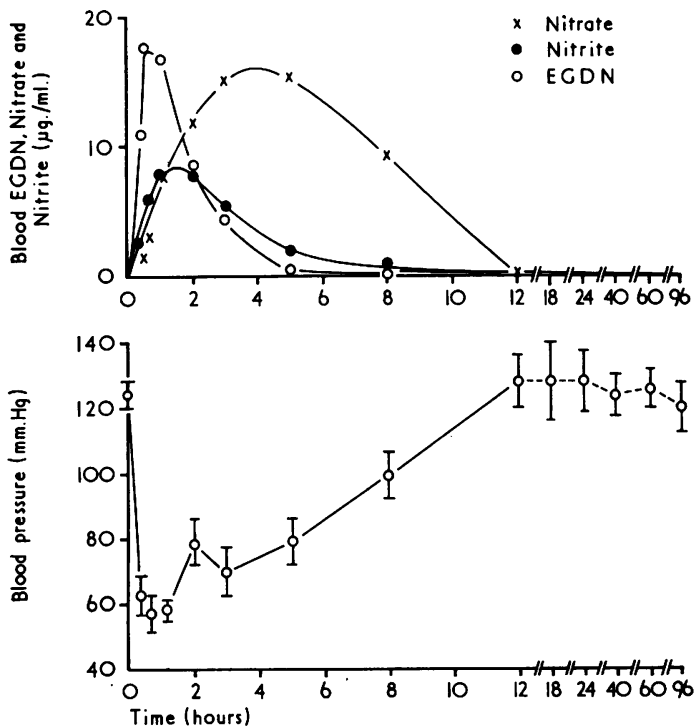

FIG. I. The blood pressure changes and the blood levels of EGDN, inorganic nitrate, and inorganic nitrite after a subcutaneous injection of $65 \mathrm{mg} . / \mathrm{kg}$. EGDN in the rat. Each point is the mean of five estimations. The mean coefficients of variation of the points on the curves are $29 \%$ for EGDN, $32 \%$ for nitrate, and $22 \%$ for nitrite.

the blood reached a peak 30 minutes after injection and fell to zero eight hours later. Inorganic nitrite was maximal at one to two hours, falling to zero at 12 hours, whereas nitrate rose more slowly to its maximum at three to five hours, reaching preinjection levels again 12 hours after the injection. There were then no further changes in the blood levels of EGDN, inorganic nitrate and nitrite up to 96 hours after the injection. There was a marked fall in blood pressure occurring promptly after the injection and reaching its lowest value at 30 minutes. There was then a significant secondary fall in blood pressure at two to three hours, followed by a steady rise to reach the control, or pre-injection, level at I2 hours.

A further group of rats was injected with a similar dose of EGDN and blood taken at the standard times for EGMN analysis. The results (Table II) show that EGMN was produced rapidly, reaching a peak at about three hours and then falling almost to zero within 12 hours.

The behaviour of EGMN in vivo was studied in a group of 40 rats by injecting each rat subcutaneously with $46 \mathrm{mg}$. $/ \mathrm{kg}$. EGMN (the theoretical yield of EGMN from the breakdown of $65 \mathrm{mg}$. $/ \mathrm{kg}$. EGDN). Blood pressure was recorded and blood samples were again taken at the various time intervals after injection and analysed for EGMN and inorganic nitrate and nitrite. The results summarized in Fig. 2, show that EGMN reached a peak in the blood at 30 minutes and fell to zero at five hours. Inorganic nitrate reached its maximal concentration two to three hours after the injection and was still present in significant quantities in the blood at eight hours, when the last sample of blood was taken. Only small quantities of inorganic nitrite were released, the concentration in the blood rising slowly to reach a maximum of $\mathrm{I} \cdot 5 \mu \mathrm{g} . / \mathrm{ml}$. after one to two hours. At eight hours no inorganic nitrite could be detected in the blood. Within Io seconds of the injection of EGMN the blood pressure started falling, reaching a minimum value at approximately two hours and returning to preinjection levels at eight hours.

Since inorganic nitrite was released during the metabolism of both EGDN and EGMN, its effects on the blood pressure were studied by slowly infusing various concentrations of sodium nitrite into the femoral vein of anaesthetized rats. The 

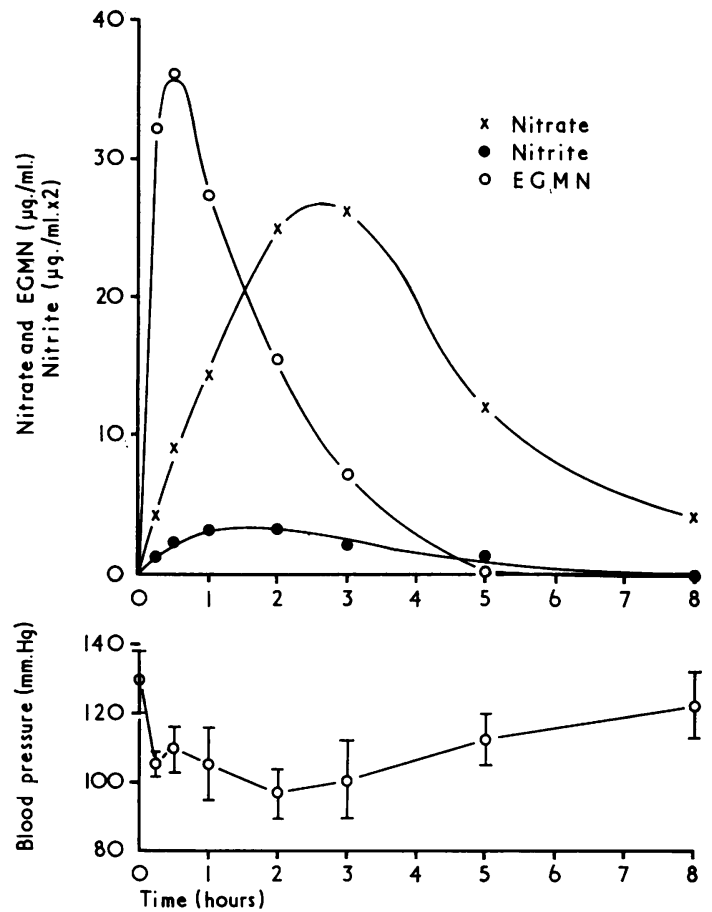

FIG. 2. The blood pressure changes and the blood levels of EGMN, inorganic nitrate, and inorganic nitrite after a subcutaneous injection of $46 \mathrm{mg}$. $/ \mathrm{kg}$. EGMN in the rat. Each point is the mean of five estimations. The mean coefficients of variation of the points on the curves are $14 \%$ for EGMN, $28 \%$ for nitrate, and $11 \%$ for nitrite.

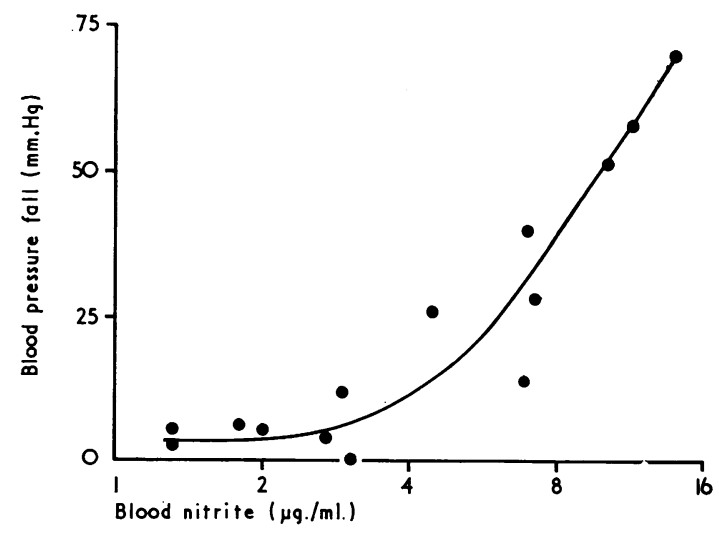

FIG 3. The fall in blood pressure and the blood nitrite concentrations following the infusion of various concentrations of sodium nitrite in the anaesthetized rat. Each point represents one experiment. blood pressure was recorded continuously. After Io minutes the infusion was stopped, the fall in blood pressure noted, and the concentration of inorganic nitrite in the blood determined. From Fig. 3 it can be seen that the blood pressure fell only slightly until a blood nitrite concentration of $3.0 \mu \mathrm{g} . / \mathrm{ml}$. was reached, when there was a marked fall in blood pressure with increasing concentrations of nitrite.

The metabolism of EGDN in the rabbit was similar to that in the rat. Two female rabbits were injected subcutaneously with $270 \mathrm{mg}$. $/ \mathrm{kg}$. EGDN, and one hour later blood was taken. Analysis of the blood showed the presence of $40.6 \mu \mathrm{g}$. $/ \mathrm{ml}$. EGDN together with $26.3 \mu \mathrm{g}$. $/ \mathrm{ml}$. inorganic nitrite and $34^{\circ} \circ \mu \mathrm{g} . / \mathrm{ml}$. inorganic nitrate.

Excretion Groups of six rats were given $65 \mathrm{mg}$. $/ \mathrm{kg}$. EGDN subcutaneously and the pooled urine was collected for periods of 24 hours. The results of the analysis (Table III) demonstrated that neither inorganic nitrite nor EGDN, and only very small quantities of EGMN, were excreted. The

\section{TABLE III}

ANALYsis of URINe EXCRETed OVER a 24-HOUR PERIOD FOLLOWING A SubCUTANEOUS INJECTION OF 65 Mg./KG. EGDN IN A GROUP OF 6 RATS

\begin{tabular}{ll|r|r}
\hline \multicolumn{1}{c|}{ Compound } & $\begin{array}{r}\text { 24-hour Excretion } \\
\text { (mg.) }\end{array}$ & $\begin{array}{r}\text { \% of Original } \\
\text { Injection Excreted }\end{array}$ \\
\hline EGDN $\ldots$ & $\ldots$ & 0.0 & 0.0 \\
EGMN $\ldots$ & $\ldots$ & 1.0 & 1.5 \\
Inorganic nitrate & $\ldots$ & 42.5 & 58.0 \\
Inorganic nitrite & $\ldots$ & $<0.1$ & $<0.1$ \\
Total recovery & $\ldots$ & 43.5 & 59.5 \\
\hline
\end{tabular}

The results are the means of two experiments.

major metabolite was inorganic nitrate. Excretion was complete at 24 hours since no further increase in metabolites above control levels could be detected in the urine up to $\mathbf{7 2}$ hours.

Similar results were obtained after a subcutaneous injection of $46 \mathrm{mg}$. $/ \mathrm{kg}$. EGMN. No inorganic nitrite could be detected in the urine and only $0.4 \%$ of the injected EGMN was excreted as EGMN. The major metabolite was again inorganic nitrate, comprising $56.5 \%$ of the original injection.

\section{Discussion}

The results of the in vitro and in vivo experiments show that EGDN is metabolized to EGMN and 
inorganic nitrate with inorganic nitrite appearing temporarily during the course of metabolism.

This may be represented schematically:

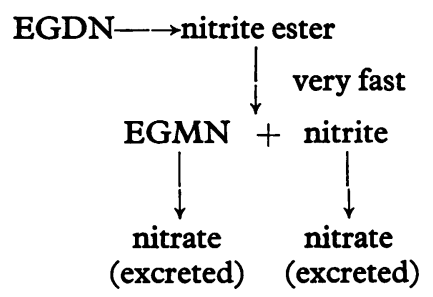

The nitrite ester would be formed by reduction of a nitrate group in EGDN, hydrolysis then yielding EGMN and inorganic nitrite. Metabolism via a nitrite ester has been suggested for nitroglycerine (Heppel and Hilmoe, 1950). If EGDN undergoes a similar reaction, the nitrite ester must be very unstable as we were unable to detect any in the blood of rats at $0.5,15,30$ or 60 minutes after injection of EGDN. It has been shown that inorganic nitrite is rapidly oxidized to nitrate in blood (Heppel and Porterfield, 1949; Litchfield, 1967). Consequently it does not appear as a final metabolite in vitro nor is it excreted in vivo.

The liberation of inorganic nitrite during the metabolism of EGDN is consistent with work on other organic nitrates such as erythritol tetranitrate and pentaerythritol tetranitrate (Yagoda and von Oettingen, 1944) and nitroglycerine (Needleman and Hunter, 1965), when inorganic nitrite was found both in vitro and in vivo. However, our results differ from the findings of Hasegawa and Sato (1963a, b), who found that inorganic nitrite was not liberated after an injection of EGDN in the rabbit. This disagreement cannot be due to a species difference, because when we repeated our experiments with the rabbit, large amounts of inorganic nitrite were detected in the blood. The disagreement may be due to the methods of analysis used, but since Hasegawa and Sato have not published their nitrite method in detail, it is not possible to clarify this point.

The results we obtained for normal blood nitrate levels also disagree with those published by the Japanese workers (Hasegawa et al., 1962; Hasegawa and Sato, 1963a). Their nitrate values are 20 times greater than the values we found for rat, rabbit, and man, and much greater than values previously reported for man, which have ranged from I $\mu \mathrm{g}$. $/ \mathrm{ml}$. (Carr, I958) to $3 \cdot 2$ to $6 \cdot 2 \mu \mathrm{g} . / \mathrm{ml}$. (Cass and Cohen, I96I).

Most of the inorganic nitrate resulting from the metabolism of EGDN must derive from the oxidation of inorganic nitrite. It is possible that some might be formed by a direct hydrolysis of the EGDN molecule, but there is no evidence to support this from the present study or from the literature. Inorganic nitrate is relatively resistant to further metabolism (Greene and Hiatt, 1954) and, once produced, is excreted in the urine. Since only $60 \%$ of the administered EGDN nitrate grouping appears as inorganic nitrate in the urine, a proportion of these nitrate groups must be metabolized to nitrogen compounds other than EGMN and inorganic nitrite.

The removal of one nitrate group from the EGDN molecule in vivo yields EGMN, which is itself metabolized, since only small quantities appear in the 24-hour urine of rats dosed with EGDN. Metabolism was confirmed when EGMN was administered in vivo. Large quantities of inorganic nitrate were produced and less than $0.5 \%$ of the injection could be recovered in the urine as the intact molecule. As EGMN is only metabolized slowly by blood in vitro, some other organ, such as the liver, must be responsible for the rapid in vivo metabolism. Breakdown of the EGDN molecule could be expected to yield ethylene glycol, and approximately $10 \%$ of an injection of EGDN was, in fact, excreted as ethylene glycol in the rat urine (unpublished data). Further experiments are now in progress to identify and estimate other metabolites that may be formed.

The metabolism of EGDN is typical of that of a lipid-soluble compound in that more polar compounds are produced during the course of metabolism, and these are then excreted by the kidneys. It differs, however, from the metabolism of nitroglycerine where the dinitrates resulting from the removal of one nitrate group are resistant to further degradation and are therefore excreted (Needleman and Krantz, 1965). EGDN metabolism resembles more closely that of pentaerythritol tetranitrate, when the stepwise removal of nitrate groups yields pentaerythritol which is excreted (DiCarlo, Hartigan, and Phillips, 1965). It is known that the liver enzyme nitroglycerine reductase, which is involved in the breakdown of nitroglycerine, is not specific (Heppel and Hilmoe, 1950) and it has been suggested that it is also involved in the breakdown of pentaerythritol tetranitrate (DiCarlo et al., 1965). It is therefore possible that the same enzyme is also concerned with the metabolism of EGDN.

In common with other organic nitrates, an injection of EGDN or EGMN causes vasodilatation and leads to a fall in the mean blood pressure. In the experiments reported here, EGDN was more effective than EGMN in lowering the blood 
pressure, but an accurate assessment of their relative potency is not possible without complete dose-response curves.

The cause of the fall in blood pressure after an injection of EGMN cannot be determined with certainty since the intact molecule of EGMN, inorganic nitrate, and inorganic nitrite are all present in the blood stream during the time of maximal depression of the blood pressure. Inorganic nitrate is generally regarded as being pharmacologically inert (Goodman and Gilman, 1965) and is unlikely to influence the blood pressure in these experiments. Inorganic nitrite, however, is a wellknown vasodilator and the results presented here show that infusion of sodium nitrite leads to a marked fall in blood pressure once the blood concentration rises above $3 \mu \mathrm{g}$. $/ \mathrm{ml}$. Since the peak blood nitrite reached during the metabolism of EGMN is only $1.5 \mu \mathrm{g} . / \mathrm{ml}$., this suggests that the metabolically released nitrite is unlikely to be responsible for the observed fall in blood pressure, which is therefore probably due to the intact molecule of EGMN. This view is supported by the observation that the blood pressure fell within 30 seconds of the injection of EGMN, at which time no inorganic nitrite could be detected in the blood. Such a view is consistent with the opinion that the intact molecule of an organic nitrate, such as nitroglycerine, is itself pharmacologically active (Krantz, Lu, Bell, and Cascorbi, 1962). However, the possibility that the nitrite ion may influence the fall in blood pressure after an injection of EGMN cannot be definitely dismissed. If some metabolism of EGMN occurs within the smooth muscle cells of the blood vessels, the nitrite released intracellularly may be more effective in reducing the blood pressure than the nitrite in the blood stream after an infusion of sodium nitrite.

When the fall in blood pressure after an injection of EGDN is considered, a further factor is introduced by the presence in the blood of unchanged EGDN in addition to EGMN and inorganic nitrite released during metabolism. Inorganic nitrite is present in relatively large quantities. Its peak concentration in the blood coincides with a fall in blood pressure of 45 to $65 \mathrm{~mm} . \mathrm{Hg}$. A similar concentration of nitrite, due to an infusion of sodium nitrite, results in a fall of approximately $40 \mathrm{~mm} . \mathrm{Hg}$. Nitrite released during the metabolism of EGDN may, therefore, play an important part in the depression of the blood pressure. However, it cannot be responsible for the fall in blood pressure immediately after the injection of EGDN since the blood pressure fell markedly within 30 seconds, yet no trace of nitrite could be found in the blood. This part of the fall must be due to the intact molecule of EGDN. EGMN also appears in the blood in large quantities two to three hours after an injection of EGDN, reaching a maximum concentration coincident with a secondary fall in blood pressure. The concentration of EGMN then falls slowly, reaching zero as the blood pressure reaches its pre-injection level. Since EGMN is capable of reducing the blood pressure, this secondary fall in blood pressure may represent the point at which the influence of EGMN becomes dominant over EGDN and inorganic nitrite, with the blood pressure being subsequently determined by the concentration of EGMN in the blood. However, the possibility that the secondary fall in pressure is due to a temporary failure of the blood pressure compensatory mechanisms cannot be entirely excluded.

Mr. J. Turbet, of I.C.I. Nobel Division, supplied the EGDN and Mr. G. H. Walker, of these laboratories, synthesized the EGMN.

\section{REFERENCES}

Carmichael, P., and Lieben, J. (1963). Arch. environm. Hlth, $7,424$.

Carr, C. J. (1958). Int. Rec. Med., 171, 121.

Cass, L. J., and Cohen, J. D. (196r). Curr. ther. Res., 3, 23.

DiCarlo, F. J., Hartigan, J. M., and Phillips, G. E. (1965). Proc. Soc. exp. Biol. (N.Y.), 118, 514.

Ferris, A. F., McLean, K. W., Marks, I. G., and Emmons, W. D. (1953). F. Amer. chem. Soc., 75, 4078.

Gage, J. C. (1961). Brit. F. industr. Med., 18, 287.

Goodman, L. S., and Gilman, A. (1965). The Pharmacological Basis of Therapeutics. 3rd ed., p. 737. Macmillan, New York.

Greene, I., and Hiatt, E. P. (1954). Amer. F. Physiol., 176, 463.

Gross, E., Bock, M., and Hellrung, F. (1942). Arch. exp. Path. Pharmak., 200, 271.

Hasegawa, H., and Sato, M. (1963a). Ind. Hlth, 1, 20.

- and - (1963b). F. Biochem. (Tokyo), 54, 58 .

- - Yoshikawa, H., Sakabe, H., Yamaguchi, M., and Hotta, K. (1962). Bull. nat. Inst. industr. Hlth, 8, ro.

Heppel, L. A., and Hilmoe, R. J. (1950). F. biol. Chem., 183, 129.

-, and Porterfield, V. T. (1949). Ibid., 178, 549.

Krantz, J. C., Lu, G. G., Bell, F. K., and Cascorbi, H. F. (I962). Biochem. Pharmacol., I1, 1095.

Litchfield, M. H. (1967). Analyst, 92, 132.

Needleman, P., and Hunter, F. E. (1965). Mol. Pharmacol., I, 77.

-, and Krantz, J. C. (1965). Biochem. Pharmacol., 14, 1225.

Shinn, M. B. (1941). Industr. Engng. Chem. Analyt. Ed., 13, 33.

Williams, A. F., Murray, W. J., and Gibb, B. H. (1966). Nature, $210,816$.

Yagoda, H., and von Oettingen, W. F. (1944). Publ. Hlth Bull. (Wash.), No. 282, p. 8. 